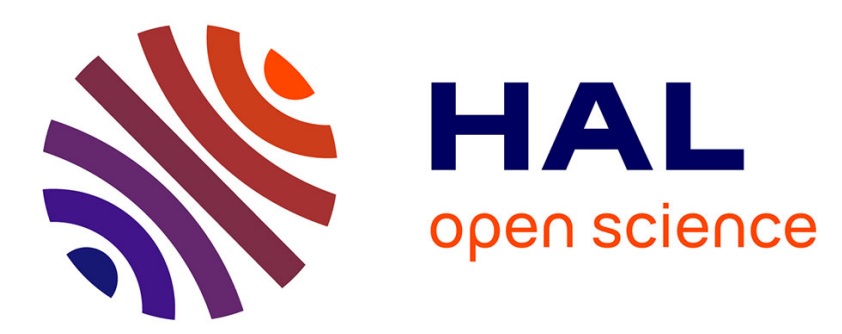

\title{
Fracture examination in concrete through combined digital image correlation and acoustic emission techniques
}

Syed Yasir Alam, Jacqueline Saliba, Ahmed Amine Loukili

\section{- To cite this version:}

Syed Yasir Alam, Jacqueline Saliba, Ahmed Amine Loukili. Fracture examination in concrete through combined digital image correlation and acoustic emission techniques. Construction and Building Materials, 2014, 69, pp.232-242. 10.1016/j.conbuildmat.2014.07.044 . hal-02444543

\section{HAL Id: hal-02444543 \\ https://hal.science/hal-02444543}

Submitted on 23 Jan 2020

HAL is a multi-disciplinary open access archive for the deposit and dissemination of scientific research documents, whether they are published or not. The documents may come from teaching and research institutions in France or abroad, or from public or private research centers.
L'archive ouverte pluridisciplinaire HAL, est destinée au dépôt et à la diffusion de documents scientifiques de niveau recherche, publiés ou non, émanant des établissements d'enseignement et de recherche français ou étrangers, des laboratoires publics ou privés.

\section{(c)(1)}

Distributed under a Creative Commons Attribution| 4.0 International License 


\title{
Fracture examination in concrete through combined digital image correlation and acoustic emission techniques
}

\author{
Syed Yasir Alam ${ }^{\mathrm{a}, \mathrm{b}, *}$, Jacqueline Saliba ${ }^{\mathrm{a}}$, Ahmed Loukili ${ }^{\mathrm{a}}$ \\ a L'UNAM Université, Institut de Recherche en Génie Civil et Mécanique (GeM), UMR-CNRS 6183, Ecole Centrale de Nantes, Nantes, France \\ ${ }^{\mathrm{b}}$ National University of Computer and Emerging Sciences, Department of Civil Engineering, Lahore, Pakistan
}

In order to build sustainable structures, the study of mechanical behavior must integrate with local phenomena, e.g. fracture propagation and localization zone. Fracture in concrete usually develops in the form of localized zone of microcracks which then coalesce into macrocrack of significant crack openings. In this paper, fracture process in geometrically scaled concrete beams under bending test is analyzed. Acoustic emission (AE) and digital image correlation (DIC) techniques are simultaneously applied to identify fracture parameters such as crack openings and size of fracture zone. The AE technique is useful to identify the location of fracture growth due to microcracks and macrocrack, however, DIC is useful to measure crack openings at various locations of crack. The location of crack tip is also estimated from both techniques. It is observed that the two techniques in coupled position proved effective in identifying the fracture process zone and cracking mechanisms of concrete.

\section{Introduction}

Cracking in concrete is a major problem in the design and durability of concrete structures. Various experimental methods already employed to detect the fracture process as the holographic interferometry, the dye penetration, the scanning electron microscopy, the acoustic emission, etc. Such methods offer either the images of the material surface to observe micro-features of the concrete with qualitative analysis, or the black-white fringe patterns of deformation on the specimen surface, from which it is difficult to observe profiles of the cracked material.

In this study, growth of fracture zone is investigated using synchronized and simultaneous observation with the digital image

\footnotetext{
* Corresponding author at: Institut de Recherche en Génie Civil et Mécanique (GeM), UMR-CNRS 6183, Ecole Centrale de Nantes, 1 rue de Noë, 44321 Nantes, France. Tel.: +33 (0) 240371660 .

E-mail addresses: syed-yasir.alam@ec-nantes.fr, syedyasiralam@gmail.com (S.Y. Alam).
}

correlation (DIC) and acoustic emission (AE). Both techniques allow a continuous and a real time data acquisition and thus the damage evolution during the load test can be recorded. The AE technique is a passive method that has been proved to be very effective to locate microcracks and sometimes measure fracture process zone (FPZ) inside the concrete structure [1-4]. It presents a large potential of applications and has been used in the past to study influence of different parameters on FPZ, such as effect of aggregate [5-7], porosity [8], the specimen geometry and type of loading [9]. The damage is then evaluated based on statistical analysis and measurement of energy or the number of AE events [10-12]. However, the spatial distribution of damage has not been precisely located.

DIC technique gives high resolution measurement of the surface displacement field. Based on this later, the fracture lengths and the cumulative crack openings of microcracks present in the FPZ can be easily determined [13-18]. Even so, this method is only limited to the surface of the specimen which does not really represent the population of cracks inside the specimen and inaccessible areas are 
still unknown. Also displacement field is incapable to give information about the development and size of fracture process zone. Therefore, it is interesting to apply simultaneously DIC and AE techniques. Aggelis et al. [19] have recently used this method to analyze the effect of reinforcement on the cracking in reinforced concrete. The recent work of Rouchier et al. [20] has also investigated the simultaneous use of digital image correlation and acoustic emission for the monitoring of progressive damage development in fiber reinforced mortar.

In case of quasi-brittle materials such as concrete, problem of the size effect appears on the mechanical response of the structures. The nominal strength decreases with the increase in size of structure and extrapolation from laboratory specimens to real structures is a major question [21]. In order to improve our understanding of the fracture process and reduce the ambiguity in the modeling of the size effect, local quantities such as the spatial distribution of microcracking and fracture measurements such as fracture process zone size and crack openings patterns are interesting to measure at the same time on a single test. This can be done by simultaneous application of DIC and AE techniques.

In the light of the above mentioned facts, the main objective of this paper is to present an experimental approach to study the evolution of fracture process zone size and crack openings in scaled concrete beams by comparing and correlating the results obtained from DIC and AE technique. In the following, at first material and experimental methods are presented. Secondly, fracture measurements are made and analyzed at important loading stages with simultaneous AE and DIC techniques. Finally, the size effect on fracture growth is described based on the experimental observations.

\section{Experimental program}

\subsection{Materials properties}

ASTM type I cement with 28 days strength of $52.5 \mathrm{MPa}$ was used. Coarse aggregates were crushed limestone with maximum size of $20 \mathrm{~mm}$ and fine aggregate were crushed fine sand of maximum size not greater than $4 \mathrm{~mm}$. The mix proportion is shown in Table 1 . The mechanical properties of concrete were determined at 28 days on three $\varnothing 110 \times 220 \mathrm{~mm}^{2}$ cylinders with a compressive strength $\left(f_{c}^{\prime}\right)$ of $45 \mathrm{MPa}$, a tensile strength $\left(f_{t}\right)$ of $3.5 \mathrm{MPa}$ assessed through splitting tests and a dynamic elastic modulus $\left(E_{d y n}\right)$ of $38 \mathrm{GPa}$ determined with a non-destructive method (Grindosonic ${ }^{\circledR}$ ).

\subsection{Specimen preparation}

Three sizes of specimens, geometrically similar in two dimensions, were prepared. The dimensions of the beams were selected in accordance with RILEM recommendations [22] of size effect method. The beams are classified into three classes depending upon their dimensions and are designated as D1, D2 and D3 for small, medium and large sizes respectively. The cross section of the specimens was rectangular and the span to height ratio was $l / D=3: 1$ for all the specimens (Fig. 1). The cross sectional heights $(D)$ of the specimens were 100, 200 and $400 \mathrm{~mm}$ respectively. The thickness (or third dimension, $b$ ) was kept constant equal to $100 \mathrm{~mm}$ for all the sizes. The beams were notched at mid-span for constant notch length to specimen height ratio $(a / D)$ of 0.2 for all the beams. The notch was created using a non stick rigid Teflon strip of $3 \mathrm{~mm}$ thickness, placed into the mould before pouring of concrete. The strip was removed with care after initial curing period of $24 \mathrm{~h}$ at $20^{\circ} \mathrm{C}$. The beams were covered with a plastic sheet during the initial curing period to avoid the surface evaporation and autogenous shrinkage cracks. The

Table 1

Concrete mixture proportions.

\begin{tabular}{ll}
\hline Constituents & Dosage $\left(\mathrm{kg} / \mathrm{m}^{3}\right)$ \\
\hline Coarse aggregate $(5-20 \mathrm{~mm})$ & 1100 \\
Sand $(0-5 \mathrm{~mm})$ & 820 \\
Cement (Portland $52.5 \mathrm{~N})$ & 312 \\
Water & 190 \\
\hline
\end{tabular}
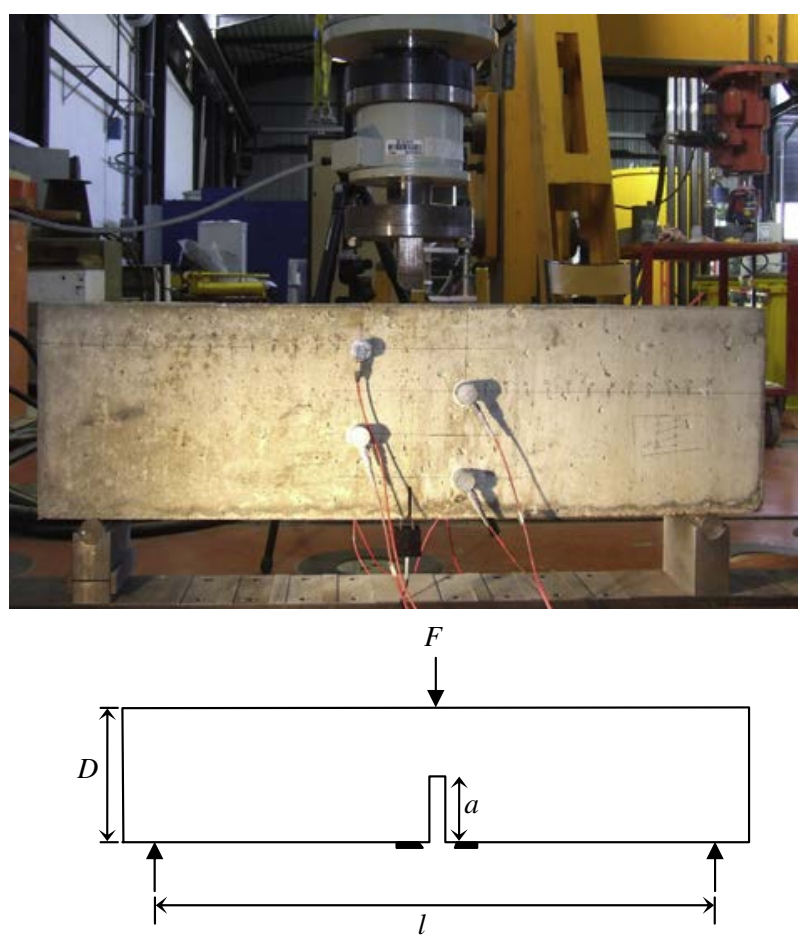

Fig. 1. Experimental setup.

beams were then kept completely submerged for 28 days in a lime water chamber controlled at $20^{\circ} \mathrm{C}$.

\subsection{Procedure for the three-point bending test}

The fracture test employs a universal testing machine as per RILEM-TMC50 recommendations. Tests were conducted on a $160 \mathrm{kN}$ capacity servo-hydraulic machine under closed-loop crack mouth opening displacement (CMOD) control. The load was applied with a CMOD rate of $0.05 \mu \mathrm{m} / \mathrm{s}$ using a CMOD gauge. Minimum number of three beams for each class was tested to study the variation of experimental results. During each test, load, crosshead displacement and CMOD were measured and recorded up to final failure with a data acquisition system. A general view of the experimental setup is provided in Fig. 1.

\subsection{Digital image correlation}

The digital images were acquired continuously as the specimen was loaded. Two digital cameras with $75 \mathrm{~mm}$ macro lens were mounted to capture images of both faces of the beam. The digital cameras have a resolution of $1040 \times 1392$ pixels and give 256 levels of gray output. Two series of tests were performed. In the first series, the cameras are mounted in order to image an area of approx. $60 \times 100 \mathrm{~mm}$ above the notch of beam. At this location, notch opening and initial crack profile were captured. For this resolution, one pixel in the image represents approx. $35 \mu \mathrm{m}$ square on the specimen, which is considered sufficient to determine a displacement measurement with $2 \mu \mathrm{m}$ accuracy [23].

In the second series, the cameras were mounted at a distance required to observe the full height of specimen (except for $D 3$ ). Thus the resolutions obtained for each size of specimen were 1 pixel $=105 \mu \mathrm{m}$ for $D 1,1$ pixel $=180 \mu \mathrm{m}$ for $D 2$ and 1 pixel $=288 \mu \mathrm{m}$ for $D 3$ specimens. Four lamps, two on either side were used to improve the luminosity of the images. The images were taken at a rate of 6 images per minute for each camera. The images were stored in the system and were analyzed afterwards. The resolution of the system depends directly on the distribution of gray levels which depends on the texture of the material. A speckle pattern of black and white paint was sprayed onto the surface of specimen to improve the displacement resolution.

\subsection{Acoustic emission (AE) method}

The AE system comprised of an eight channel AEWin system, a general-purpose interface bus ( $2 \times$ PCI-DISP4 having 4 channels each) and a PC for data storage analysis. A 3D analysis with an AEWin algorithm is performed for the localization of $\mathrm{AE}$ events. For the source to be located in $3 \mathrm{D}$, a wave must reach at least five sensors. In this study, 8 piezoelectric sensors of type R15a were used all having same frequency range of $50-200 \mathrm{kHz}$ and the same resonance frequency of $150 \mathrm{kHz}$. 
The transducers were placed around the expected location of the fracture process zone (FPZ) to minimize errors in the AE event localization. They were placed on both sides of the specimen with silicon grease as the coupling agent. Thus, the sensors form a parallelogram grid location on one side of $\left(6 \times 10 \mathrm{~cm}^{2}\right)$ for $D 1$ beams, $\left(12 \times 10 \mathrm{~cm}^{2}\right)$ for $D 2$ beams and $\left(24 \times 10 \mathrm{~cm}^{2}\right)$ for $D 3$ beams (Fig. 2).

The detected signals were amplified with a $40 \mathrm{~dB}$ gain differential amplifier. The recorded $\mathrm{AE}$ amplitudes ranged from 0 to $100 \mathrm{~dB}$. In order to overcome the background noise, the signal detection threshold was set at a value of $35 \mathrm{~dB}$ slightly above the background noise. The acquisition system was calibrated before each test using a pencil lead break procedure HSU-NIELSEN [24]. Location accuracy is measured in the range of $5 \mathrm{~mm}$ by applying the pencil load fracture at a known location of the specimen (Fig. 3).

The effective velocity and the attenuation of acoustic waves were also calculated. The effective velocity measured in our study is $3800 \mathrm{~m} / \mathrm{s}$. The hit definition time used during the tests was set at $200 \mu$ s. Signal descriptors such as rise time, counts, energy, duration, amplitude, average frequency and counts to peak were captured and calculated by AEwin system. Each waveform was digitized and stored.

\section{Results}

In this section, only the fracture process of $D 2$ beams is analyzed using AE and DIC techniques. Size effect analysis is presented separately in the next section. Fig. 4 presents the average forcecrack mouth opening displacement (CMOD) curve of $D 2$ beams. The variation between different beams is shown by gray zone.

In order to analyze the results simultaneously with the $\mathrm{AE}$ and DIC techniques, the mechanical behavior can be divided into different stages [25]: pre-peak linear phase, pre-peak non linear phase and the post-peak phase. These stages are the typical trends observed in the beams tested and are no doubt related to the crack propagation in the material but this information is not available in the mechanical curve.

\subsection{Damage localization}

During the formation of a crack, energy is emitted as an elastic wave and propagates from the crack location to the AE transducers at specimen surface. The localization map of $\mathrm{AE}$ events is based on arrival times of the first wave at each transducer and their respective velocity in concrete specimen. Once the arrival time is picked, least-square method is used to estimate the event location. Though damage accumulation with $\mathrm{AE}$ technique was detected in $3 \mathrm{D}$, the cumulative acoustic events are placed in 2D in order to compare with DIC results. The detected AE events are presented over a window covering the specimen height and a width of $200 \mathrm{~mm}$ centered at the notch. In the test described in this section, total number of $\mathrm{AE}$ events is equal to 2287. Each plotted point indicates a detected $\mathrm{AE}$ source. In addition to number of events, it is very important to investigate AE signal parameters. The initiation and propagation of cracks in concrete are generally correlated to the study of AE signals of certain amplitude. Extensive studies have shown that the absolute acoustic energy is the most important parameter to characterize an event $[26,27]$. Thus, the 2D localization maps of the events are classified in terms of their levels of energy indicating different damage mechanisms. Six energy levels are defined as shown in Fig. 5. In the beginning few events are detected at the top of the specimen result from pressing of the loading rail at the beginning of the test. AE events of higher energy levels are located in the center of the localized damaged zone or the core fracture process zone [2]. Few events are also located below the notch tip as shown in Figs. 5 and 13, which may be due to the decrease of location accuracy as the crack propagates. The accuracy depends also on many conditions such as the covering of the herd sphere, the homogeneity of concrete, and the variation in wave propagation velocity which may arise based on the number of aggregate crossings over the path of wave propagation or may be due to cracking in the specimen.

The process of DIC consists of analyzing a series of images of the specimen surface having a distributed gray level pattern. These patterns are monitored during the load application by a digital camera and stored in computer in a digital format. Displacements fields can be measured by matching the first image (or the reference image, typically corresponding to the unloaded stage) and each subsequent image. The correlation algorithm in VIC-2D determines the location of each sub-pixel in the imaging area. It provides the corresponding displacement vectors in the coordinate axis, thus displacement field on the surface of the specimen at different loading stages are obtained (Fig. 6).

Displacement fields (Fig. 6) are important in the sense that it represents displacement of each and every point in the imaging zone which enables easily to locate crack due to displacement discontinuity. Crack openings can be obtained from the displacement jump across the two sides of the crack [13]. In Fig. 7, crack openings profiles are drawn at different loading levels on both faces of the specimen. It can be noticed that the profiles are approximately the same on both sides of the specimen; however, the crack path was not same due to heterogeneous microstructure of concrete. Thus information of crack openings does not depend on the crack path and can be very useful to diagnose the overall fracture behavior of the material. It can be observed that crack
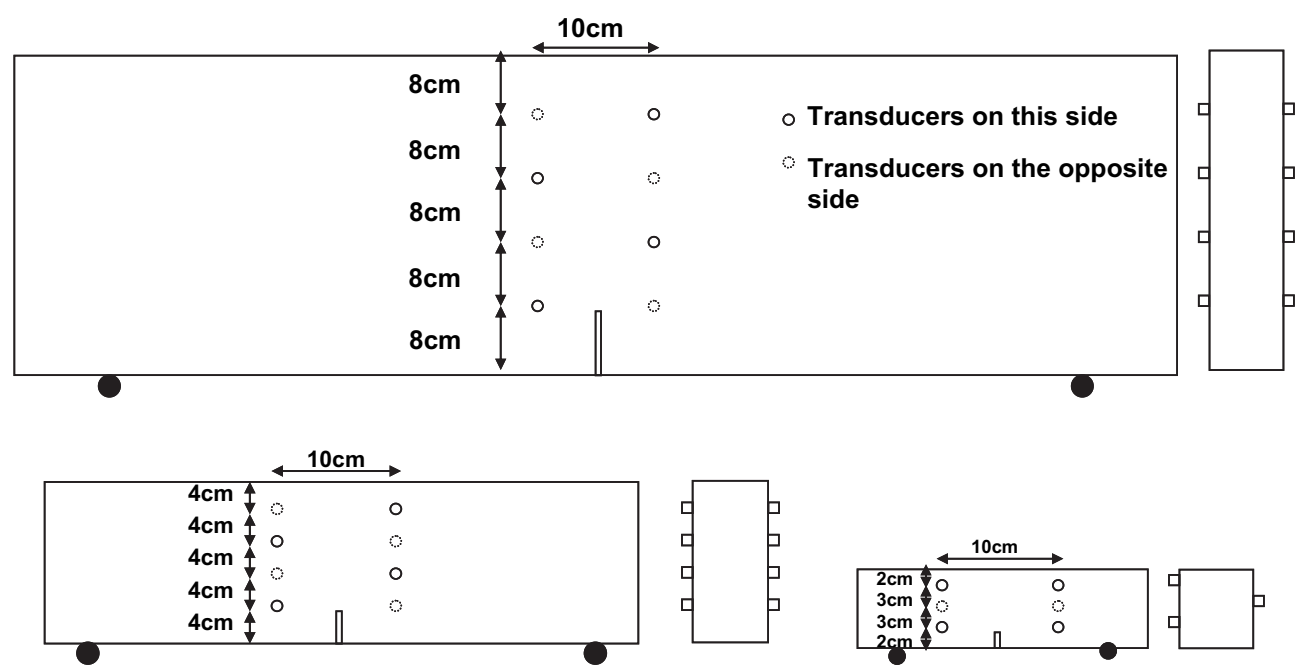

Fig. 2. Specimen geometry and $\mathrm{AE}$ transducers position for $D 1, D 2$ and $D 3$ beams. 

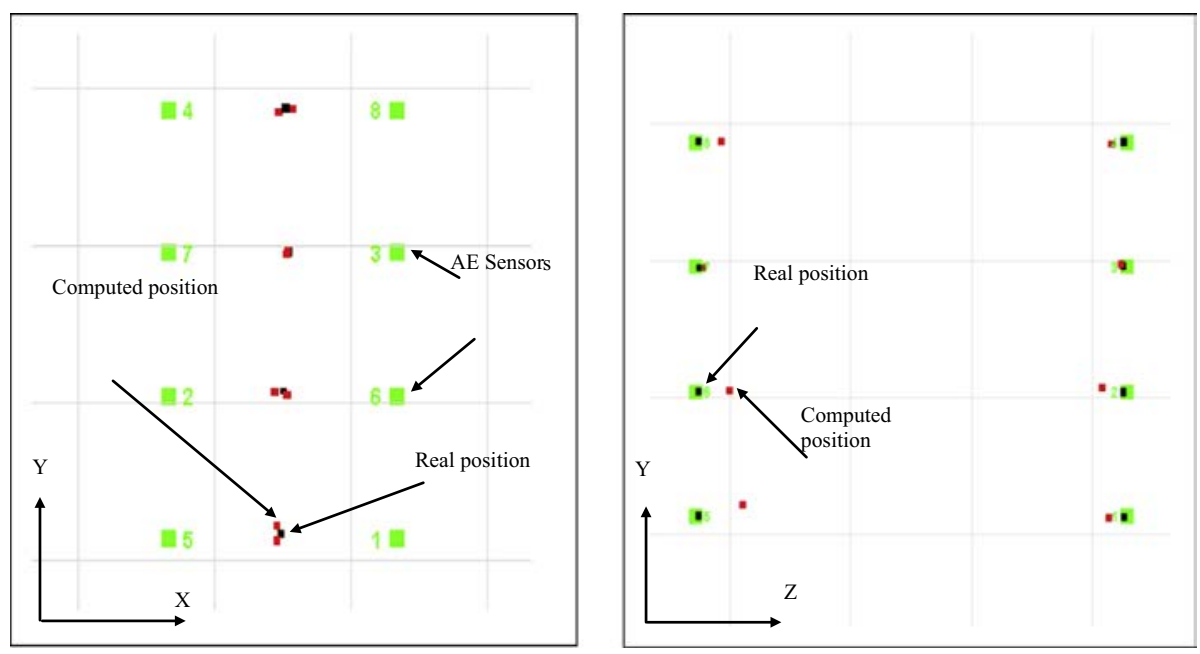

Fig. 3. Estimation of error in $A E$ source location in $D 3$ beam.

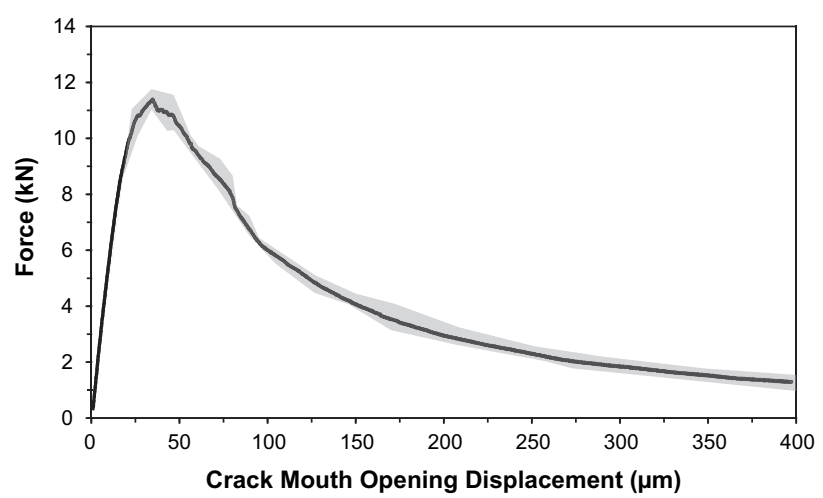

Fig. 4. Force-crack mouth opening displacement curve of $D 2$ beam.

openings vary linearly along the height of the specimen until the closure of crack. During the pre-peak phase of loading, crack openings are very small. As the load crosses the peak load crack openings start to increase at higher rate. The profiles of crack opening also allow to monitor the progression of crack in the specimen at different loading levels. Thus crack length can also be estimated which will be discussed later in Fig. 14.

In the following, different stages of fracture behavior in relation to the overall mechanical response of the beam are described.

In the first stage up to about $80 \%$ of peak load in pre-peak regime, the load-CMOD relationship is linear. During this loading stage, the bottom sensors started recording. However, the hits were of very low amplitude and only few events were detected. However, DIC shows that small crack openings at front of the notch begin to appear at $60 \%$ of peak load in pre-peak regime.

In the second stage where the load-CMOD relationship starts deviating from linearity; the load continues to increase until the peak load value is reached. The AE activity indicates formation of microcracks above the notch. Literature review [4,28] also shows that in this phase microcracks begins to appear in a somewhat random pattern in the zone of maximum tensile stress. Displacement fields from DIC shows that crack openings above the notch increases and clear macrocrack can be observed (Fig. 6a and b).

After the peak load, CMOD continues to increase and the load starts to decrease. In the initial post-peak phase, the AE activity increases rapidly (Fig. 8) and microcracks start to coalesce in a localized zone. The increase in AE activity can be associated to the creation of new large surface corresponding to the formation of macrocrack and the emission of high energetic signals [29] as shown in Fig. 8. The localization zone of the AE sources becomes wider and spread away from the notch tip following a conical progress (Fig. 5c).

During the post peak loading stage, the crack can sometimes be interlocked by an aggregate as observed by DIC. This aggregate interlock or aggregate shielding is observed in our experimental study (Figs. 9 and 10). An aggregate particle usually comes into the path and causes the crack to deflect. Sometimes aggregate particles also break due to a higher stress state in that location. In this case, aggregate interlock occurs just in front of the notch and the crack extension is almost insignificant during the phase of aggregate interlock (Fig. 10). Thus, more energy is consumed to break the crack interlock than to extend the crack across the specimen which can also explain the energy jumps observed in the evolution of the AE energy (Fig. 8).

During last stage or the terminal post-peak region, a shift in the force-CMOD relationship is observed in the tail of the curve and the $\mathrm{AE}$ activity rate decreases. AE events are generated as a consequence of different toughening mechanisms through the crack faces [30]. This final part of the curve shows a considerable increase in the crack opening, while the load decreases gradually until the specimen fails.

\subsection{Analysis of the FPZ: combination of the fracture data of DIC and AE techniques}

One objective of this analysis is to compare the characteristics of the FPZ, and more particularly to know quantitatively the change in its width and length in the different phases of rupture. Many researchers tried to set up a value for those later based on various test results. For Hillerborg et al. [31], the length of the FPZ was related to the length of cohesive zone or the characteristic length which is a pure property of the materials. The value of the length of the FPZ was also measured directly based on the distinction between the increasing zone of the local strain from the decreasing zone [32] or the energy consumed by each specimen portion based on the local deformation curve [33]. Recently, different techniques as the X-rays, the AE and DIC techniques were used [2]. Different approaches have been used to determine the length of the FPZ based on the AE technique. Lertsrisakulrat et al. [33] and Watanabe et al. [34] proposed different simplified empirical relations for the localized compressive fracture length. They considered that the length of the FPZ is equal to the zone where the local energy is superior to $15 \%$ of the total energy in the specimens 

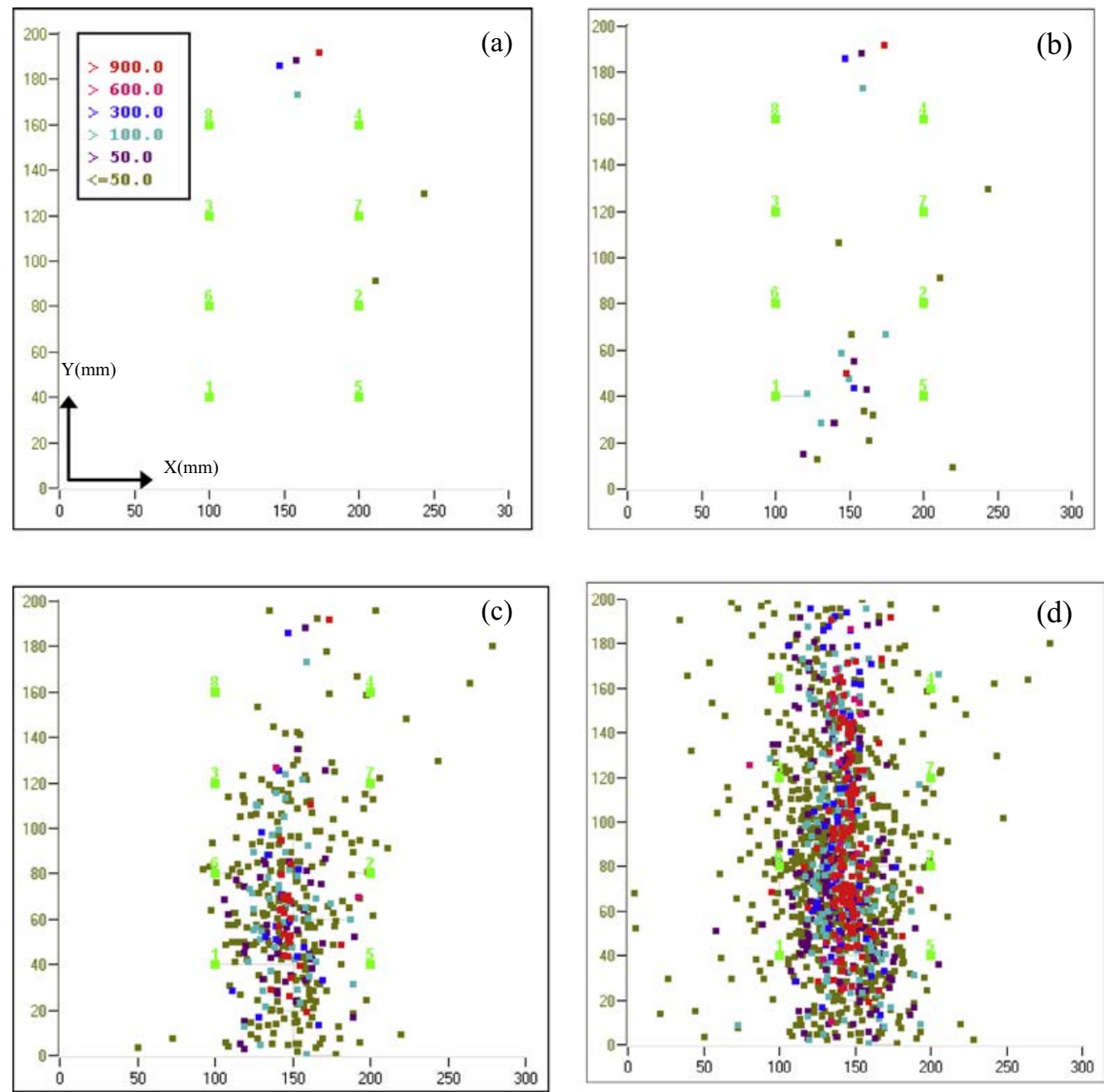

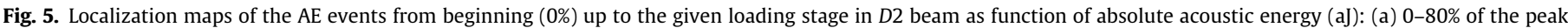
load; (b) $0-100 \%$ of the peak load; (c) $0-50 \%$ of the peak load in the post peak region; (d) up to complete failure.
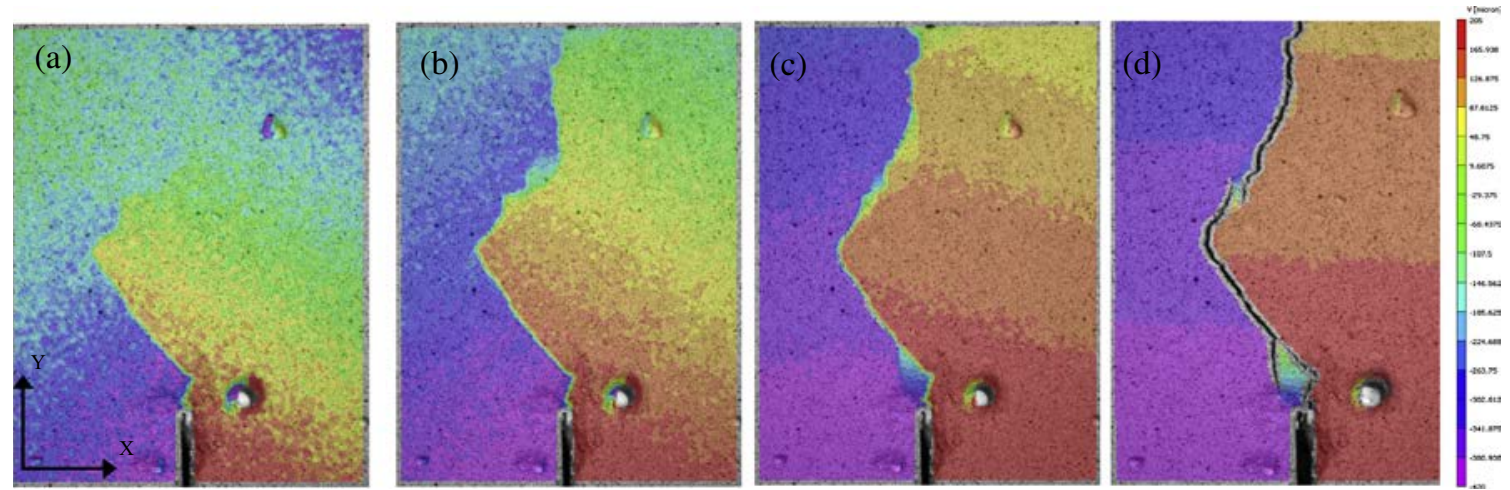


peak region; (d) displacement at the end of test.

or the region where the distribution of peak amplitude or $\mathrm{AE}$ energy is superior to $30 \%$ as the AE criterion to distinguish the failure zone. The length and the width of damage zone were also computed using probability and statistics laws by dividing the damage zone into two areas: the zone of confidence with high damage and a weak damage zone based on the distribution either of the number or the amplitude of acoustic emission events. The relation between the characteristic length and the length of the FPZ was estimated equal to $L_{\mathrm{FPZ}} \approx 0.82 l_{c h}$ while the width of the $\mathrm{FPZ}$ is equal to $2.75 D_{\text {agg }}$ [27] defined earlier as $3 D_{\text {agg }}$ [35]. Note here that the length and the width of the FPZ are strongly influenced by dimension of the specimens $[36,2]$.

The 3D location of the AE sources for specimens D2 is shown in Fig. 11 at the end of the test. As the distributions of $\mathrm{AE}$ events 


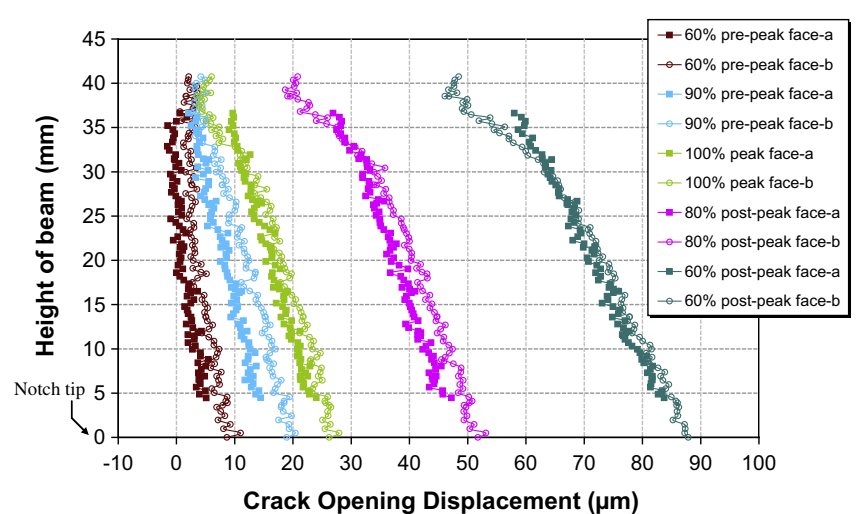

Fig. 7. Crack opening profile on two faces of $D 2$ beam.

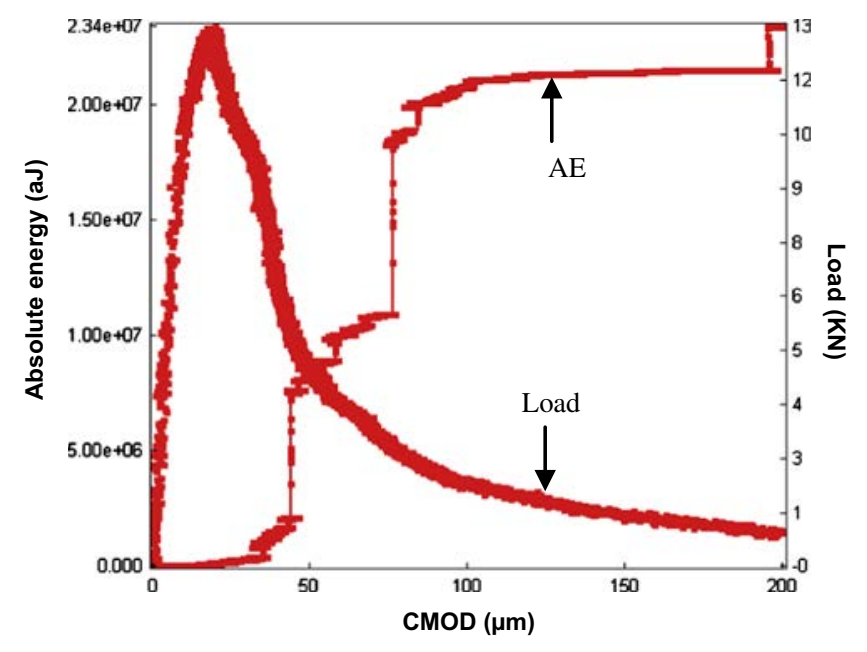

Fig. 8. Correlation of load-CMOD curve with AE energy in D2 beam.

present the same pattern as the distribution of peak amplitude and $\mathrm{AE}$ energy, the approach used here to analyze the properties of the FPZ is similar to that developed by [8]. The beam surface is divided into a two dimensional $(X Y)$ grid of square elements with uniform dimensions $\left(1 \times 1 \mathrm{~cm}^{2}\right)$. For each element the number of $\mathrm{AE}$ events is recorded. Fig. 11 shows the total number of $\mathrm{AE}$ events located inside each grid element. Greater number of events is present above the notch which shows the localization of microcracking.

In order to monitor the width of FPZ, cumulative number of $\mathrm{AE}$ events is recorded for each $X$ location. This step is performed at different loading intervals. Fig. 12 shows the cumulative number of events in the post-peak loading step. It can be seen that the number of AE events is more important in the zone above the notch and

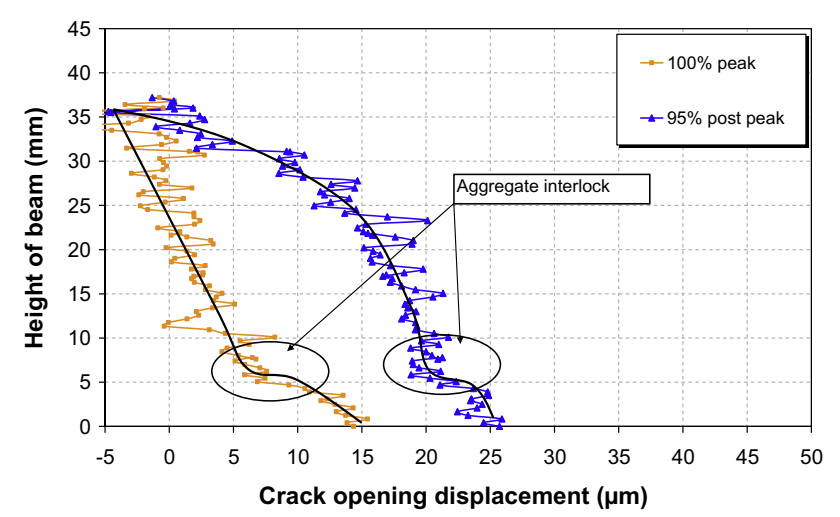

Fig. 10. Crack opening profiles showing aggregate interlock in $D 2$ beam.

decreases gradually on both sides. To evaluate the width of FPZ $\left(W_{\mathrm{FPZ}}\right)$, we consider an arbitrary horizontal line located at $20 \%$ of $N_{\max }\left(N_{\max }\right.$ corresponds to the peak of the cumulative AE events). Thus $W_{\text {FPZ }}$ can be identified as (i) the zone in which cumulative AE events at each $X$ location is more than or equal to $20 \%$ of $N_{\max }$. This zone corresponds to a zone of confidence in which the high number of events is representing localization of microcracking (ii) the zone outside the first zone, where cumulative AE events are lower than $20 \%$ of $N_{\max }$, corresponds to a lower level of damage [27]. Note here, that the zone (i) correspond to the region where $\mathrm{AE}$ events present an energy higher than 300 aJ and the total $\mathrm{AE}$ energy in this zone is higher than 95\% of the total energy defined by Otsuka in comparison with the X-rays [2].

The length of the FPZ $\left(L_{\mathrm{FPZ}}\right)$ is measured in the same way. Fig. 13 shows the cumulative number of events at each $Y$ location in a post-peak loading step. It can be seen that ahead of the notch tip, the number of $\mathrm{AE}$ events increases, attains the maximum value $\left(N_{\max }\right)$ and then decreases. Therefore, $L_{\mathrm{FPZ}}$ is taken as the length from notch tip to the intersection of the histogram with an arbitrary horizontal line located at $20 \% N_{\max }$. However, alone AE analysis does not give precise information about the tip of the stress free crack.

The progression of cracking with DIC in the beam at different loading conditions is presented in Fig. 14. From the crack opening profiles, the length of fracture zone (measured from the notch tip) can be approximately located considering where the COD becomes equal to zero (i.e. crack closure). Actually, the crack tip is "blurred" by microcracking in the fracture process zone (FPZ), therefore, the length of fracture zone measured in this way (i.e. from crack openings) is the length of the macrocrack plus the length of the FPZ where microcracks exist. The fracture zone length measured with DIC is plotted at different loading stages in correlation with the cumulated number of $\mathrm{AE}$ events (Fig. 14). Both the fracture length growth measured using DIC and the increase of total number of $\mathrm{AE}$

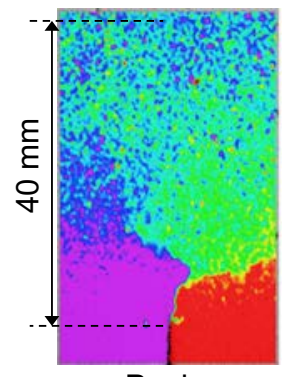

Peak

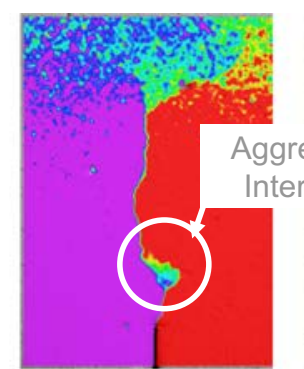

$95 \%$ post peak

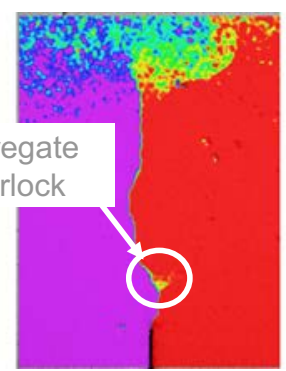

$90 \%$ post peak



$85 \%$ post peak

Fig. 9. Aggregate interlock observed by DIC in $D 2$ beam. 

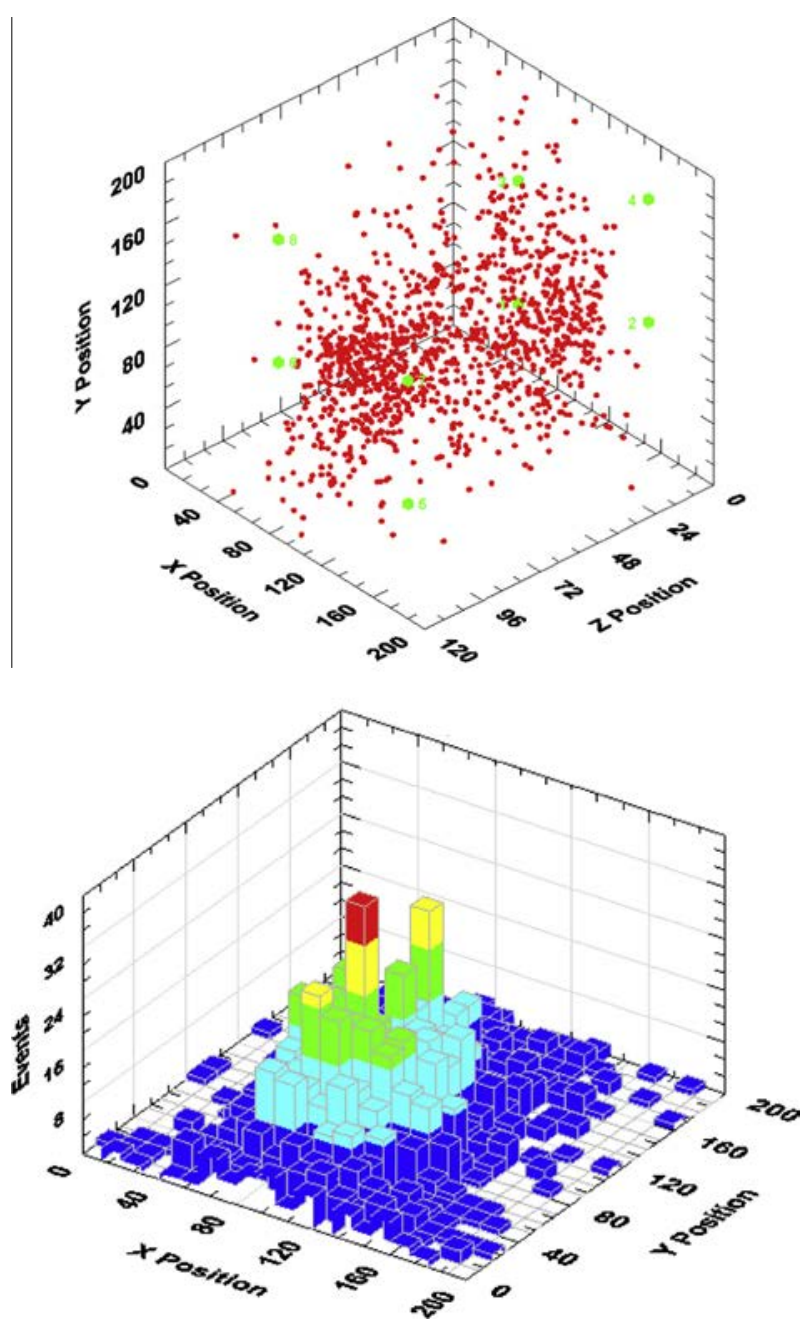

Fig. 11. (a) Localization of $A E$ events in $D 2$ beam (b) distribution of $A E$ events on the rectangular grid at final load step in $D 2$ beam.

events are the relative measure of damage accumulation in the beam.

Fig. 15 presents the comparison of the fracture length evolution as detected by DIC and AE techniques at different loading stages.
The fracture is indicated at about $60 \%$ of the peak load in the pre-peak regime with DIC technique. However, the appearance of cracking using the $\mathrm{AE}$ technique begins at $80 \%$ of the peak load in the pre-peak regime. The fracture length increases smoothly until the peak load. A sudden increase in fracture length is observed between the peak load and $80 \%$ of the peak load in the post-peak regime with both techniques. The fracture growth becomes relatively slower in the final loading stages until the specimen fails completely. We can note that the fracture length measured from DIC is always larger than AE technique. In fact, DIC measures macrocrack length plus the length of FPZ where microcracks are open or crack openings are measurable, while the length measured with the AE technique represents the fracture core zone and thus it is incapable of determining the tip of the crack precisely. The limitation of $\mathrm{AE}$ technique in crack length measurements is also due to variation acoustic parameters after cracking e.g. acoustic wave velocity. On the other hand DIC is a visual non contact method and is more reliable for length scale measurements. However, the same trend is obtained concerning the kinetics of the evolution of the fracture length with both techniques. The same methods will be used hereafter to study the size effect.

\section{Application to the size effect}

\subsection{Damage quantification}

Damage quantification for the three beams was calculated based on the total $\mathrm{AE}$ activity represented by the number of localized events. Fig. 16 represents the cumulative number of AE events in correlation with the load CMOD curves. During the loading phase up to CMOD equals to $100 \mu \mathrm{m}$ the cumulative $\mathrm{AE}$ events shows a similar behavior for all the sizes of beam. It can be explained by looking into Figs. 18 and 19a. Width of FPZ increases with increase of specimen size (Fig. 18); however, the fracture length decreases with increase of specimen size (Fig. 19a). This could result into similar cumulative $\mathrm{AE}$ events behavior for all specimen sizes. In the post-peak phase the AE activity becomes more important as size of beam increases. We can notice that the total number of $\mathrm{AE}$ events is greater in larger beams requiring higher energy for overcoming interfacial bond along the ligament length. The cumulated AE energy followed the same evolution and gives information on the cracks initiation that progress until the failure and thus could be related to the fracture energy measured on a global scale.

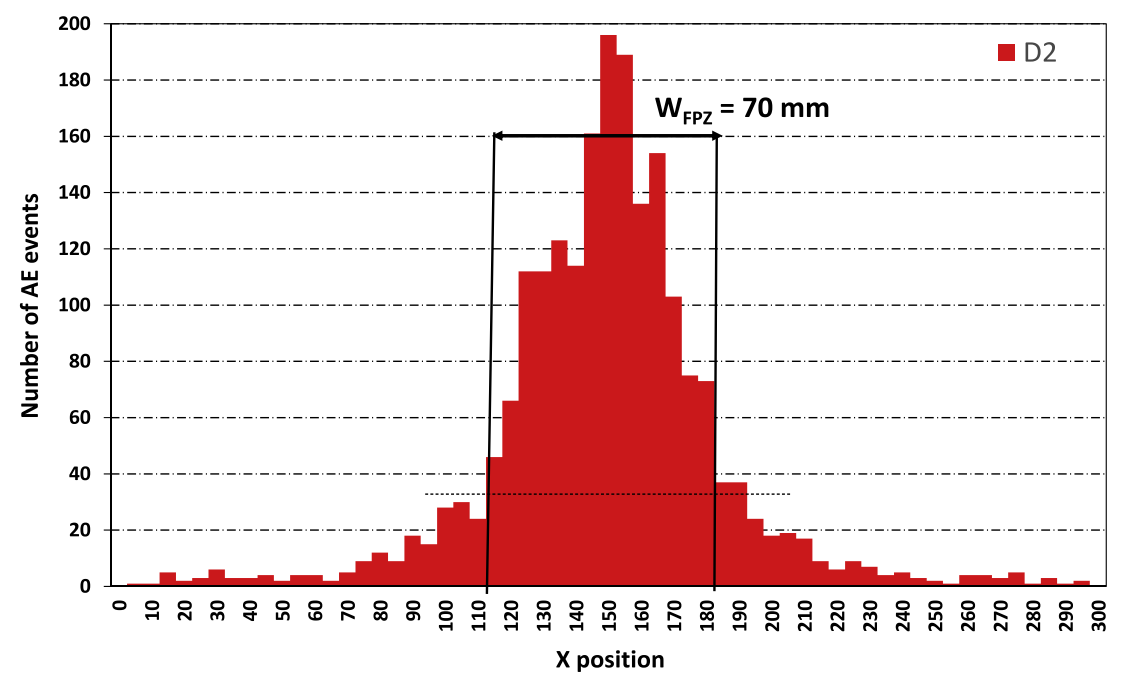

Fig. 12. Cumulative AE events at each $X$ location and calculation of $W_{\mathrm{FPZ}}$ in $D 2$ beam. 


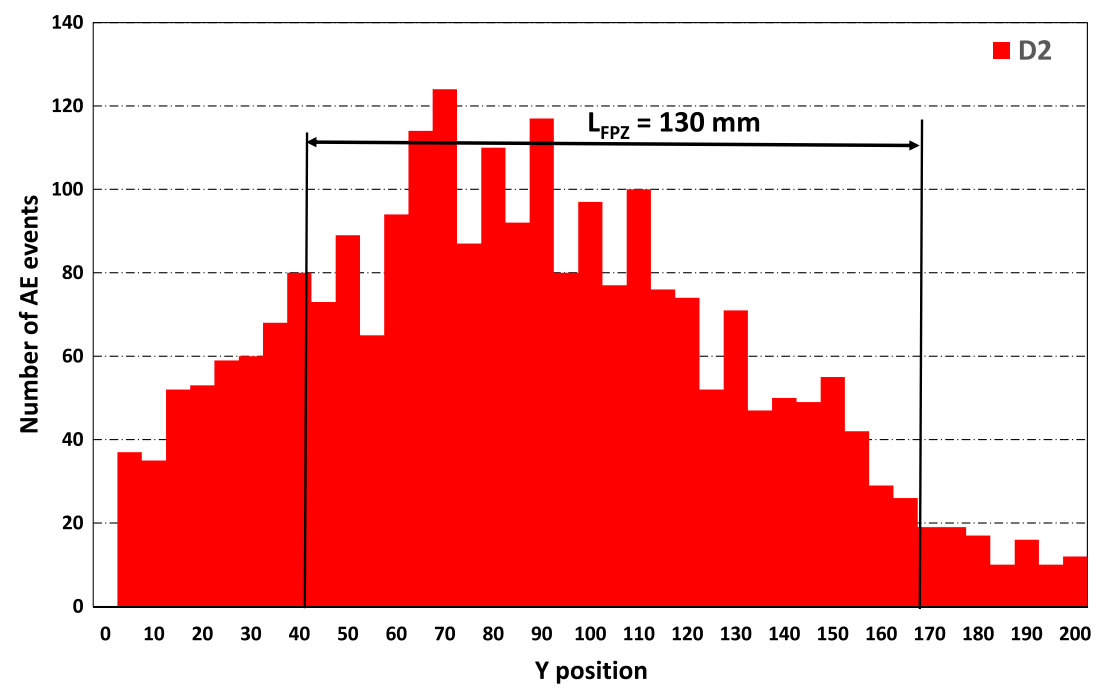

Fig. 13. Cumulative AE events at each $Y$ location and calculation of $L_{\mathrm{FPZ}}$ in $D 2$ beam.

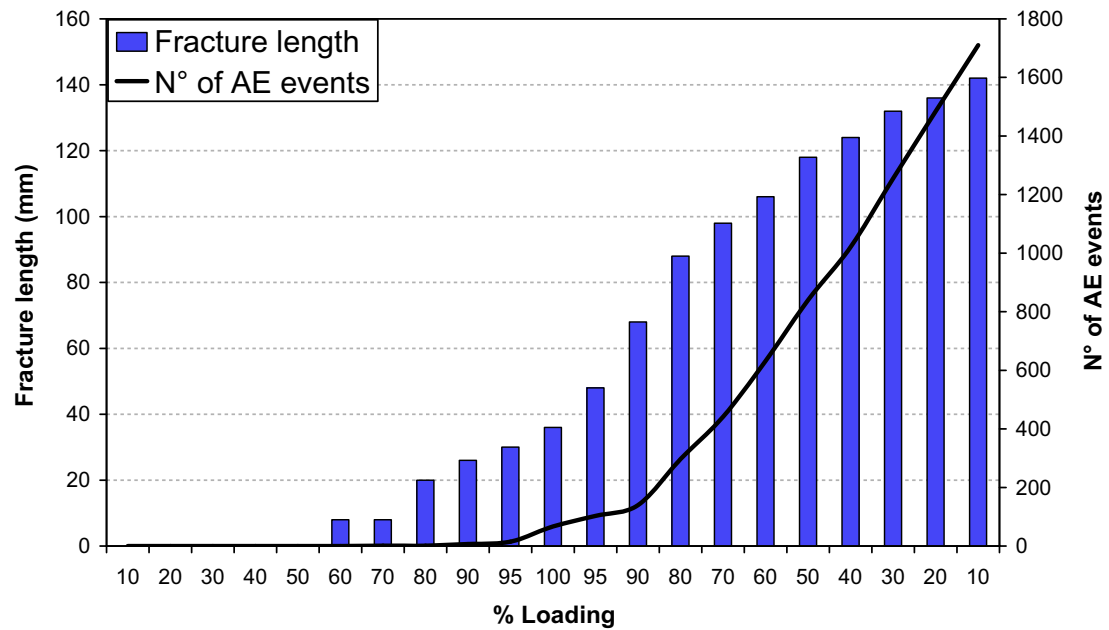

Fig. 14. Evolution of fracture length (measured using DIC) and cumulative number of AE events in $D 2$ beam.

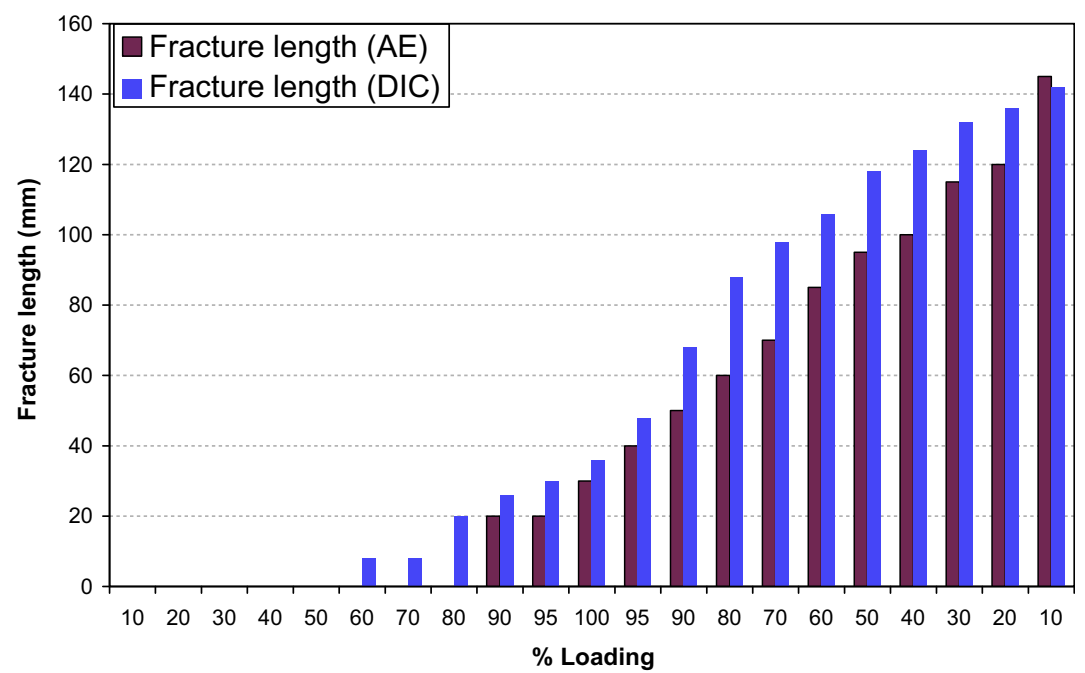

Fig. 15. Evolution of fracture length using DIC and AE techniques in D2 beam. 


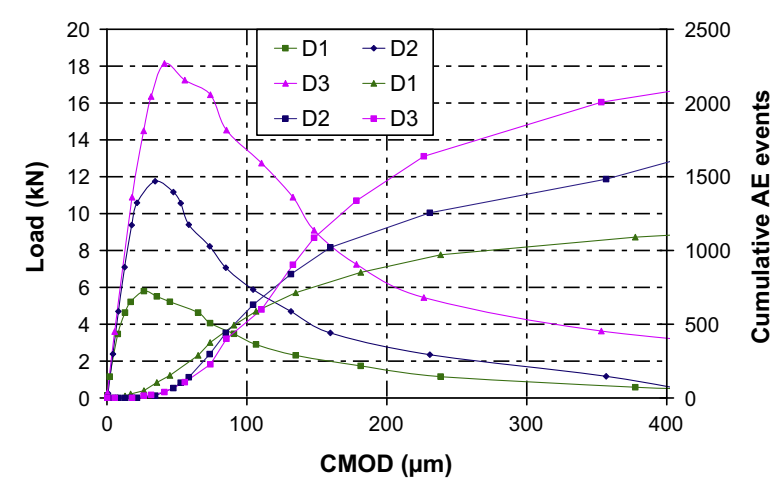

Fig. 16. Correlation of load vs. CMOD curves with the evolution of $A E$ events in $D 1$, $D 2$ and $D 3$ beams.

\subsection{Evolution of the FPZ}

The localization maps of the AE sources are drawn on the surface of all size of specimen over a window centered at notch, with a width of $100 \mathrm{~mm}$ and covering the full beam height (Fig. 17). The strain profiles also presented obtained by DIC method. Crack path can be noted, however, it should be kept in mind these are surface strain profiles on one face of the specimen and crack path on one face of the specimen may not be similar to the crack path of the other side due to the internal heterogeneity of the material and it also changes the crack path inside the specimen. It is also observed that $\mathrm{AE}$ events are detected in between two crack profiles and indicate a rough and complex fracture surface inside the specimen dominated by the distribution of aggregates and other softening mechanisms. It should be noticed that the $\mathrm{AE}$ events distribution zone is relatively wider as compared to the width of strain localization zone. Both methods are used in literature to calculate the width of FPZ $[37,1,2]$. In DIC method, strain profiles are calculated from displacement fields using the laws of continuum mechanics and the strain profiles would not be objective when there is strong discontinuity in displacement fields. Also one component of strain $\left(\varepsilon_{\mathrm{XX}}\right)$ may not be able to determine FPZ correctly when main crack branches into microcracks in multiple directions. On the other hand AE method is dependent on acoustic waves originating from microcracks and width of FPZ calculated would be relatively more reliable.

Based on these localization maps, the width of the fracture process zone $\left(W_{\mathrm{FPZ}}\right)$ is also measured. The evolution of $W_{\mathrm{FPZ}}$ using $\mathrm{AE}$ technique is shown in Fig. 18. It can be observed that $W_{\mathrm{FPZ}}$ increases with the loading level in the pre-peak region. At about $80 \%$ post-peak loading, $W_{\mathrm{FPZ}}$ starts stabilizing. Similar behavior is observed in all beam sizes. It should be noticed that up to the same loading level (80\% post-peak) in Fig. 16. AE activity shows a similar behavior for all the beam sizes.

In the pre-peak region, the width of the FPZ (Fig. 18) is more for smaller beam size. At peak load $W_{\mathrm{FPZ}}$ is same for $D 1, D 2$ and $D 3$ beams; however in the post peak loadings, $W_{\mathrm{FPZ}}$ is greater for the large beam size.

The relative fracture length $\left(L_{\text {crack }} / D\right)$ at different loading intervals obtained with the DIC and the AE techniques is plotted in Fig. 19 for each specimen size. It is the ratio of length of fracture from the crack mouth $\left(L_{\text {crack }}\right)$ to height of specimen $(D)$. The same observations are obtained with both techniques with a smaller relative fracture length with $\mathrm{AE}$ technique. In fact, the microcracks ahead of the macrocrack do not strong AE activity and thus crack length is always smaller with AE method. On the other hand, DIC method determines a longer fracture length which includes the microcracking zone. It can be seen that the formation of fracture starts before the maximum load is reached. For the smaller specimen $D 1$, fracture initiates at a lower loading in the pre-peak regime as compared to the larger specimen $D 3$. The fracture growth in the specimens can be divided into three stages. The first stage is from the fracture initiation to the peak loading. In this stage, the fracture growth is smooth. In the second stage i.e. between the peak loading and $80 \% F_{\max }$ in the post peak regime, the fracture growth is relatively abrupt and the fracture length is almost doubled. In the last stage, the crack propagation is relatively slow. We can also see that the relative fracture length in $D 1$ specimen is usually bigger as compared to $D 2$ and $D 3$. The behavior of crack extension in different sizes of specimens observed in Fig. 19 can be understood by the fact that in quasi-brittle materials, when the specimen size

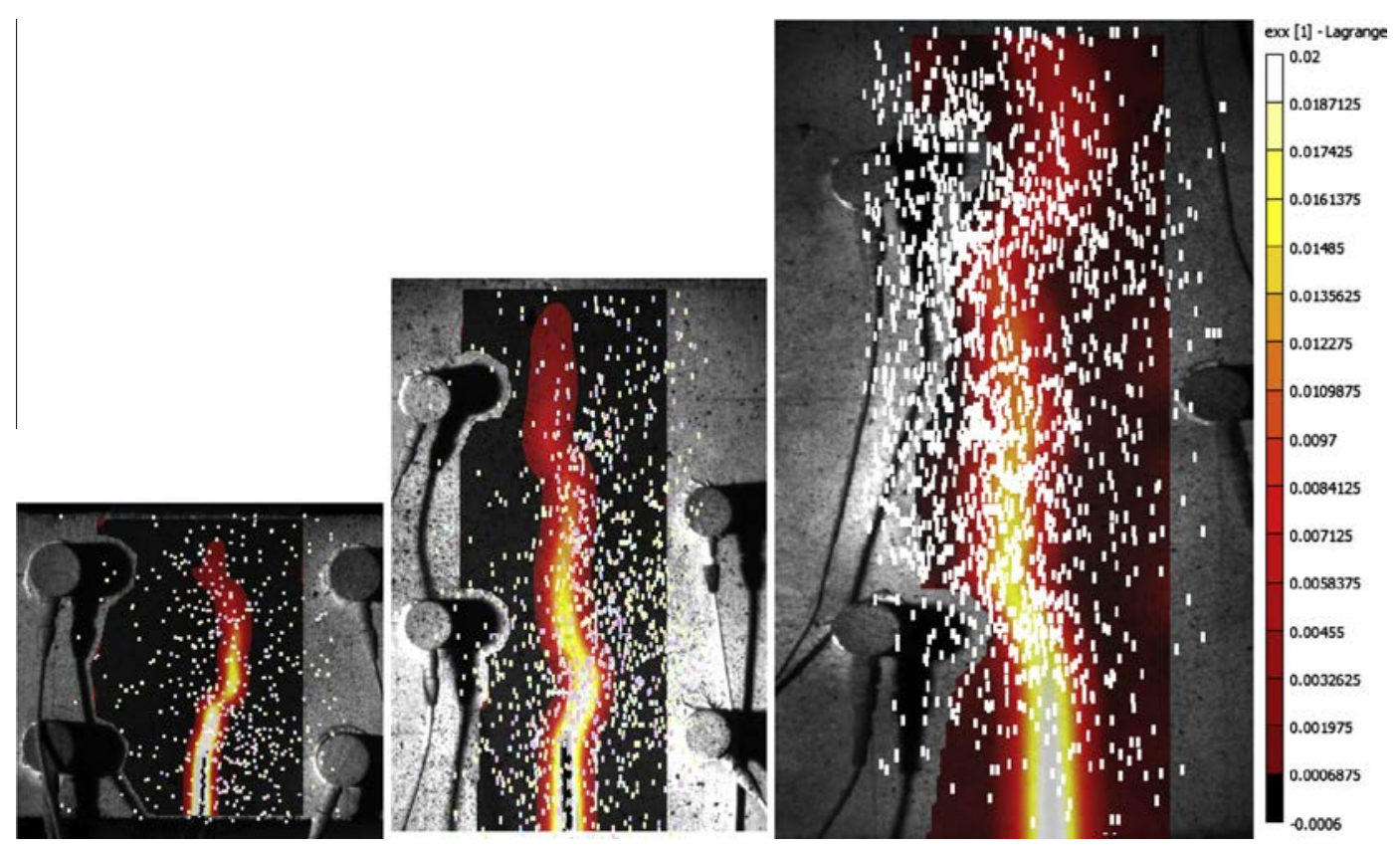

Fig. 17. Localization of $A E$ events in correlation with the strain contours ( $\left.\varepsilon_{x x}\right)$ from DIC in $D 1, D 2$ and $D 3$ beams. 


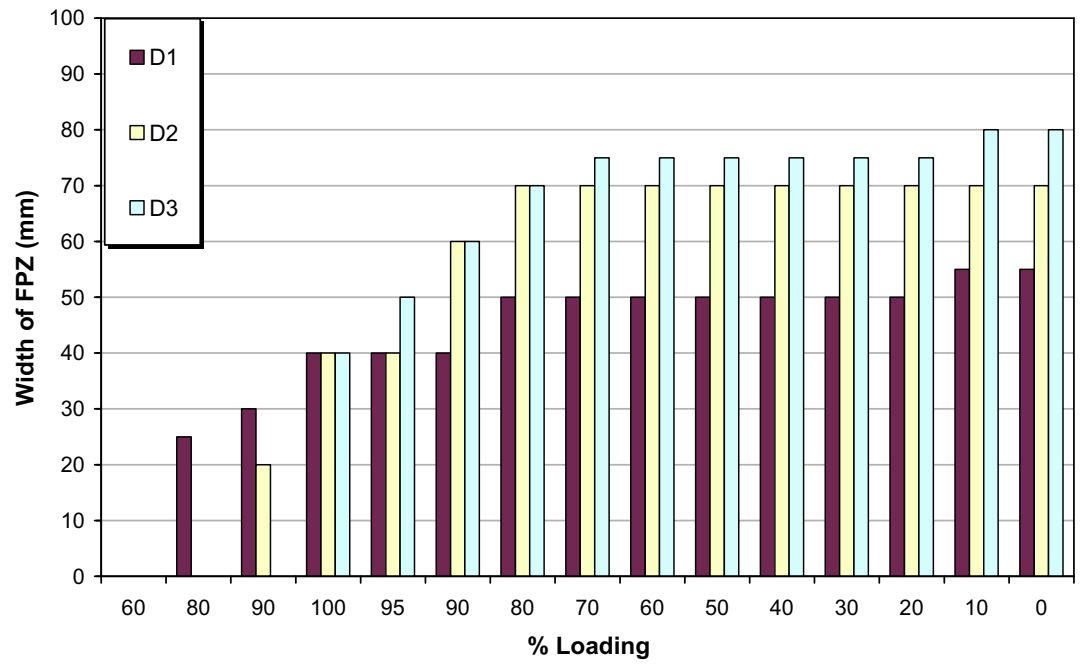

Fig. 18. Evolution of $W_{\mathrm{FPZ}}$ for $D 1, D 2$ and $D 3$ beams.
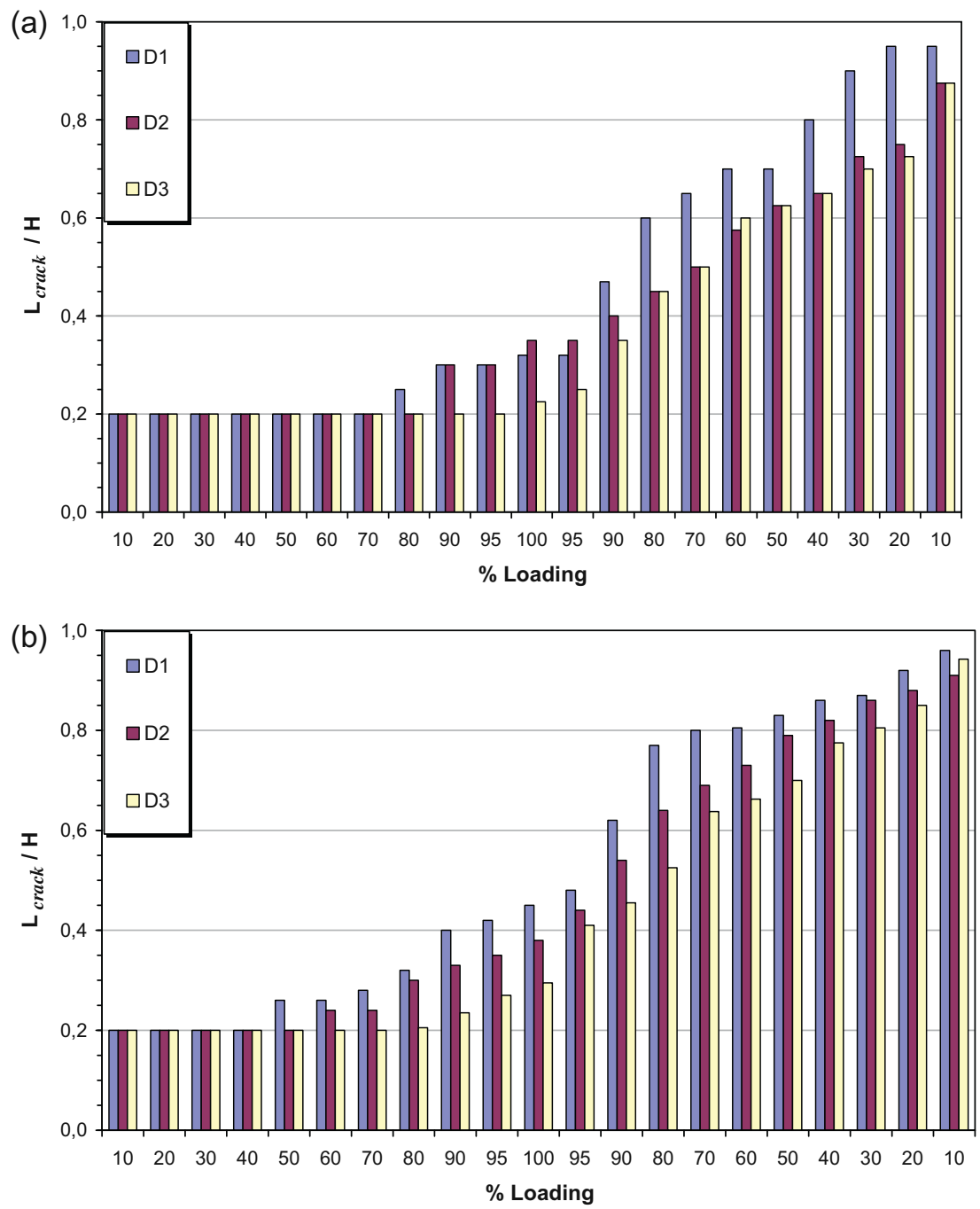

Fig. 19. Evolution of relative crack length with load steps for in D1, D2 and D3 beams using - (a) AE; (b) DIC techniques.

increases, the mechanical behavior becomes more brittle i.e. fracture initiates near the peak load and propagates abruptly in the specimen. This is due to the reason that in a larger structure more strain energy is available to drive the propagation of the failure zone. Therefore, the structure fails as soon as the fracture initiates [38]. In authors point of view, in order to understand completely the size effect on fracture initiation, tests should be carried out on notch less specimens. In this paper authors have presented 
results on notched specimens. Experiments shall be carried out on notch less specimens and will be discussed in future.

\section{Conclusion}

In this paper an experimental study is presented in order to monitor the fracture growth during three point bending tests in concrete beams. Two techniques i.e. acoustic emission (AE) and digital image correlation (DIC) were employed. It is observed that the two techniques in coupled position can be used simultaneously and proved to be very effective in identifying the fracture process zone and cracking mechanism of concrete. It is demonstrated that the global mechanical response of the beams can be translated from the local fracture process in the material. Correlation between the load-CMOD curves and AE and DIC analysis shows that macro cracks extend slightly before the load reaches its peak. DIC is an effective method to measure discontinuities such as fracture length and crack openings. Fracture process zone width and length are also monitored with $\mathrm{AE}$ technique. The evolution of the fracture length shows similar trends for both techniques. However, DIC is more helpful to measure fracture length than $\mathrm{AE}$. The reason may be that measurement of crack length from DIC is based on crack openings, while the criteria used for determining the length of the FPZ with AE may cause a loss of information as it is not possible to know exactly the crack tip.

The total number of AE events and AE energy released increases with the specimen sizes. The initiation of fracture is detected earlier in smaller specimens as compared to larger specimens, in which fracture is initiated at about $90 \%$ of the peak load. The relative crack length is always higher for the smaller specimen.

\section{References}

[1] Granger S, Loukili A, Pijaudier-Cabot G, Chanvillard G. Experimental characterization of the self-healing of cracks in an ultra high performance cementitious material: mechanical tests and acoustic emission analysis. Cem Concr Res 2007;37:519-27.

[2] Otsuka K, Date H. Fracture process zone in concrete tension specimen. Eng Fract Mech 2000;65:111-31.

[3] Chen B, Liu J. Experimental study on AE characteristics of three-point-bending concrete beams. Cem Concr Res 2004;34:391-7.

[4] Landis EN, Shah SP. The influence of microcracking on the mechanical behaviour of cement based materials. Cem Based Mater 1995;2:105-18.

[5] Wu K, Chen B, Yao W. Study of the influence of aggregate size distribution on mechanical properties of concrete by acoustic emission technique. Cem Concr Res 2001;31:919-23.

[6] Chen B, Liu J. Effect of aggregate on the fracture behavior of high strength concrete. Constr Build Mater 2004;18:585-90.

[7] Mihashi H, Nomura N, Niiseki S. Influence of aggregate size on fracture process zone of concrete detected with three dimensional acoustic emission technique. Cem Concr Res 1991;21(5):737-44.

[8] Haidar K, Pijaudier-Cabot G, Dubé JF, Loukili A. Correlation between the internal length, the fracture process zone and size effect in model materials. Mater Struct 2005;38:201-10.

[9] Labuz JF, Cattaneo S, Chen L. Acoustic emission at failure in quasi-brittle materials. Constr Build Mater 2001:15:225-33.

[10] Wu K, Chen B, Yao W. Study on the AE characteristics of fracture process of mortar, concrete and steel-fiber-reinforced concrete beams. Cem Concr Res 2000;30:1495-500.

[11] Soulioti D, Barkoula NM, Paipetis A, Matikas TE, Shiotani T, Aggelis DG. Acoustic emission behavior of steel fibre reinforced concrete under bending. Constr Build Mater 2009;23:3532-6.
[12] Grosse CU, Fink F. Quantitative evaluation of fracture processes in concrete using signal-based acoustic emission techniques. Cem Concr Compos 2006;28:330-6

[13] Alam SY, Loukili A, Grondin F. Monitoring crack openings in concrete beams with different sizes using digital image correlation technique. Eur J Environ Civil Eng 2012;16(7). 818-813.

[14] Choi S, Shah SP. Measurement of deformations on concrete subjected to compression using image correlation. Exp Mech 1997;37:307-13.

[15] Hall SA, Bornert M, Desrues J, Pannier Y, Lenoir N, Viggiani G, et al. Discrete and continuum analysis of localised deformation in sand using X-ray micro CT and volumetric digital image correlation. Géotechnique 2010;60:315-22.

[16] Hild F, Roux S, Guerrero N, Marante ME, Flórez-López J. Calibration of constitutive models of steel beams subject to local buckling by using digital image correlation. Eur J Mech A Solids 2011;30(1):1-10.

[17] Lawler JS, Keane DT, Shah SP. Measuring three-dimensional damage in concrete under compression. ACI Mater J 2001:98(6):465-75.

[18] Luo P, Chao Y, Sutton M, Peters W. Accurate measurement of threedimensional deformations in deformable and rigid bodies using computer vision. Exp Mech 1993:33:123-32.

[19] Aggelis DG, Verbruggen S, Tsangouri S, Tysmans T, Van Hemelrijck D Characterization of mechanical performance of concrete beams with external reinforcement by acoustic emission and digital image correlation. Constr Build Mater 2013:47:1037-45.

[20] Rouchiera S, Forayb G, Godinb N, Woloszyna M, Rouxa J-J. Damage monitoring in fibre reinforced mortar by combined digital image correlation and acoustic emission. Constr Build Mater 2013;38:371-80.

[21] Bazant ZP. Size effect in blunt fracture: concrete, rock, metal. J Eng Mech (ASCE) 1984;110(4):518-35

[22] RILEM 50-FMC Recommendation,. Determination of fracture energy of mortar and concrete by means of three-point bend test on notched beams. Mater Struct $1985 ; 18: 285-90$

[23] Corr D, Accardi M, Graham-Brady L, Shah SP. Digital image correlation analysis of interfacial debonding properties and fracture behavior in concrete. Eng Fract Mech 2007;74(1-2):109-21.

[24] RILEM TC212-ACD Recommendation,. Acoustic emission and related NDE techniques for crack detection and damage evaluation in concrete. Mate Struct 2010:43:1177-81.

[25] Saliba J, Loukili A, Grondin F, Regoin J-P. Influence of basic creep on cracking of concrete shown by the acoustic emission technique. Mater Struc 2012;45:1389-401.

[26] Muralidhara S, Raghu Prasad BK, Eskandari H, Karihaloo B. Fracture process zone size and true fracture energy of concrete using acoustic emission. Const Build Mater. 2010;24:479-86.

[27] Hadjab HS, Thimus JF, Chabaat M. The use of acoustic emission to investigate fracture process zone in notched concrete beams. Curr. Sci. 2007;93(5):648-53.

[28] Li Z, Shah SP. Localization of microcracking in concrete under uniaxial tension. ACI Mater J 1994;91(4):372-81.

[29] Kim B, Weiss WJ. Using acoustic emission to quantify damage in restrained fiber-reinforced cement mortars. Cem Concr Res 2003;33:207-14.

[30] Shah SP, Ouyang C. Fracture mechanics for failure of concrete. Annu Rev Mater Sci 1994;24:293-320.

[31] Hillerborg A, Modéer M, Petersson PE. Analysis of crack formation and crack growth in concrete by means of fracture mechanics and finite elements. Cem Concr Res 1976;6:773-82.

[32] Nakamura H, Higai T. Compressive fracture energy and fracture zone length of concrete, JCI-C51E Seminar on post-peak behavior of RC structures subjected to seismic loads 1999;2:259-272.

[33] Lertsrisakulrat T, Watanabe K, Matsuo M, Niwa J. Experimental study on parameters in localization of concrete subjected to compression. J Mater Conc Struct, Pavements, JSCE 2001:50(669):309-21.

[34] Watanabe K, Niwa J, Iwanami M, Yokota H. Localized failure of concrete in compression identified by AE method. Constr Build Mater 2003;18(3):189-96.

35] Bazant ZP, Kazemi MT. Determination of fracture energy process zone length and brittleness number from size effect with application to rock and concrete. Int J Fract 1990;44:111-31.

[36] Zhang D, Wu K. Fracture process zone of notched three-point bending concrete beams. Cem Concr Res 1999;29:1887-92.

[37] Skarzynski L, Syroka E, Tejchman J. Measurements and calculations of the width of the fracture process zones on the surface of notched concrete beams. Strain 2009;47:319-32.

[38] Bazant ZP, Planas J. Fracture and size effect in concrete and other quasibrittle materials, vol. 16. CRC Press; 1997. 